\title{
Estimation of Quantal Size and Number of Functional Active Zones at the Calyx of Held Synapse by Nonstationary EPSC Variance Analysis
}

\author{
Alexander C. Meyer, Erwin Neher, and Ralf Schneggenburger \\ Max-Planck-Institut für biophysikalische Chemie, Abteilung Membranbiophysik, D-37077 Göttingen, Germany
}

At the large excitatory calyx of Held synapse, the quantal size during an evoked EPSC and the number of active zones contributing to transmission are not known. We developed a nonstationary variant of EPSC fluctuation analysis to determine these quantal parameters. AMPA receptor-mediated EPSCs were recorded in slices of young (postnatal 8-10 d) rats after afferent fiber stimulation, delivered in trains to induce synaptic depression. The means and the variances of EPSC amplitudes were calculated across trains for each stimulus number. During $10 \mathrm{~Hz}$ trains at $2 \mathrm{~mm} \mathrm{Ca}^{2+}$ concentration ( $\left[\mathrm{Ca}^{2+}\right]$ ), we found linear EPSC variance-mean relationships, with a slope that was in good agreement with the quantal size obtained from amplitude distributions of spontaneous miniature EPSCs. At high release probability with 10 or $15 \mathrm{~mm}\left[\mathrm{Ca}^{2+}\right]$, competitive antagonists were used to partially block EPSCs. Under these conditions, the EPSC variance-mean plots could be fitted with pa- rabolas, giving estimates of quantal size and of the binomial parameter $N$. With the rapidly dissociating antagonist kynurenic acid, quantal sizes were larger than with a slowly dissociating antagonist, suggesting that the effective glutamate concentration was increased at high release probability. Considering the possibility of multivesicular release and moderate saturation of postsynaptic AMPA receptors, we conclude that the binomial parameter $N(637 \pm 117$; mean \pm SEM) represents an upper limit estimate of the number of functional active zones. We estimate that during normal synaptic transmission, the probability of vesicle fusion at single active zones is in the range of $0.25-0.4$.

Key words: synaptic transmission; short-term depression; quantal analysis; release probability; glutamate spillover; postsynaptic currents; AMPA receptor
The large glutamatergic synapse formed by calyx of Held nerve terminals onto principal cells of the medial nucleus of the trapezoid body (MNTB) has been used in recent years to study the mechanisms of synaptic transmission and its short-term plasticity (Forsythe et al., 1998; Schneggenburger et al., 1999; Wu and Borst, 1999; Takahashi et al., 2000; Sakaba and Neher, 2001; Sun and $\mathrm{Wu}, 2001)$. Nevertheless, important questions regarding the quantal properties of synaptic transmission at the calyx of Held synapse remain unaddressed. Thus, although quantal sizes have been estimated by sampling spontaneously occurring, miniature EPSCs (mEPSCs) in previous work, it is not known whether quanta add linearly to make up an evoked EPSC. In fact, recent evidence (Sakaba and Neher, 2001; Sun and Wu, 2001) suggests that with strong presynaptic stimulation, substantial desensitization and saturation of postsynaptic AMPA receptors (AMPARs) occurs at the calyx of Held synapse. Also, the number of active zones from which transmitter release occurs has not been estimated by functional assays, although it is known from morphological studies that this number must be quite large (Lenn and Reese, 1966; Lübke et al., 2000; Rowland et al., 2000).

Here, we have used EPSC fluctuation analysis (Silver et al., 1998) (for review, see Clements and Silver, 2000) to estimate the

\footnotetext{
Received May 14, 2001; revised July 20, 2001; accepted July 26, 2001.

This work was supported by the Deutsche Forschungsgemeinschaft (SFB 406). We thank Takeshi Sakaba and Julia Trommershäuser for fruitful discussions throughout the course of this study, Felix Felmy, Volker Scheuss, and Angus Silver for helpful comments on this manuscript, and Volker Scheuss for help with model calculations.

Correspondence should be addressed to Dr. Ralf Schneggenburger, Abteilung Membranbiophysik (140), Max-Planck-Institut für biophysikalische Chemie, D-37077 Göttingen, Germany. E-mail: rschneg@gwdg.de.

Copyright (ㄷ) 2001 Society for Neuroscience $0270-6474 / 01 / 217889-12 \$ 15.00 / 0$
}

quantal size during evoked synaptic transmission and the number of functional active zones at the calyx of Held synapse. We have devised a novel, nonstationary variant of EPSC fluctuation analysis (see also Scheuss and Neher, 2001), in which trains of presynaptic stimuli were used to induce synaptic depression in regular intervals. Assuming that synaptic depression is caused by a reduction in quantal content (von Gersdorff et al., 1997; Schneggenburger et al., 1999; Weis et al., 1999; Takahashi et al., 2000), this protocol should allow us to lead the synapse repetitively through different states of release probability. The mean EPSC amplitude and its variance were calculated for each EPSC in depressing trains, and EPSC variance versus mean (variancemean) plots were generated.

Under conditions of "normal" extracellular $\mathrm{Ca}^{2+}$ concentration ( $\left[\mathrm{Ca}^{2+}\right] ; 2 \mathrm{mM}$ ), we found linear EPSC variance-mean plots, with slopes similar to quantal sizes estimated from the mean of mEPSC amplitude distributions. By elevating $\left[\mathrm{Ca}^{2+}\right]$ drastically (up to $15 \mathrm{~mm}$ ), we observed that the EPSC variance-mean plots went through a clear maximum. Under these conditions, however, we also obtained evidence for a reduced quantal size late in trains, when depression of EPSCs was strong, revealing a contribution of postsynaptic mechanisms to synaptic depression (Trussell et al., 1993; Otis et al., 1996). EPSC variance-mean relationships at high $\left[\mathrm{Ca}^{2+}\right]$ were fitted by parabola functions and were interpreted assuming binomial statistics of transmitter release (Quastel, 1997; Silver et al., 1998). We discuss that the resulting binomial parameter $N$, which was $\approx 600$ on average, can be regarded as an upper limit estimate of the number of functional active zones contributing to transmission at the calyx of Held synapse. 


\section{MATERIALS AND METHODS}

Slice preparation and electrophysiology. Transverse brainstem slices of 200 $\mu \mathrm{m}$ thickness were prepared from 8- to 10 -d-old Wistar rats, with day 0 referring to the date of birth. Slices were kept in a Ringer's solution containing (in mM): $125 \mathrm{NaCl}, 25 \mathrm{NaHCO}_{3}, 2.5 \mathrm{KCl}, 1.25 \mathrm{NaH}_{2} \mathrm{PO}_{4}, 1$ $\mathrm{MgCl}_{2}, 2 \mathrm{CaCl}_{2}, 25$ glucose, 0.4 ascorbic acid, 3 myo-inositol, and 2 Na-pyruvate, $\mathrm{pH} 7.4$, when bubbled with $95 \% \mathrm{O}_{2}$ and $5 \% \mathrm{CO}_{2}$. During experiments, $50 \mu \mathrm{M}$ D-AP-5 was added to the bath solution. In control conditions $\left(2 \mathrm{~mm}\left[\mathrm{Ca}^{2+}\right], 1 \mathrm{~mm}\left[\mathrm{Mg}^{2+}\right]\right)$, the composition of the Ringer's solution was as given above. For conditions of high release probability, the extracellular solution contained $10 \mathrm{mM} \mathrm{CaCl}_{2}$ and $1 \mathrm{~mm} \mathrm{MgCl}_{2}$. In later experiments in which an even higher release probability was intended, a $\mathrm{Mg}^{2+}$-free solution was used containing (in $\mathrm{mM}$ ): $150 \mathrm{NaCl}, 10$ HEPES, $2.5 \mathrm{KCl}, 10$ glucose, and $15 \mathrm{CaCl}_{2}, \mathrm{pH}$ 7.4. Experiments were done at room temperature $\left(21-24^{\circ} \mathrm{C}\right)$.

Afferent presynaptic axons were stimulated with a bipolar platinumiridium electrode, placed $\sim 300 \mu \mathrm{m}$ medial from the MNTB. Postsynaptic principal cells of the MNTB were identified in an upright microscope equipped with infrared differential interference contrast (Zeiss, Oberkochen, Germany) and a contrast-enhanced video system (Hamamatsu, Tokyo, Japan). Cells that showed a clear presynaptic and postsynaptic spike in extracellular recordings after afferent fiber stimulation $(\approx 10-20 \%$ of the population of cells close to the surface of the slice) were selected for subsequent recording (Borst et al., 1995). Wholecell patch-clamp recordings were made at a holding potential of $-80 \mathrm{mV}$ with an EPC-9 patch-clamp amplifier (Heka Elektronik, Lambrecht, Germany; membrane potentials not corrected for liquid junction potentials). The pipette solution contained (in mM): $130 \mathrm{Cs}$-Gluconate, 20 TEA-Cl, 10 HEPES, $5 \mathrm{Na}_{2}$-phosphocreatine, $4 \mathrm{Mg}$-ATP, $0.3 \mathrm{GTP}$, and 5 EGTA, pH 7.2. Pipette resistances were 3-4 M , resulting in series resistances $\left(R_{\mathrm{s}}\right)$ of $4-8 \mathrm{M} \Omega$ at the beginning of recordings.

The large EPSC amplitudes at the calyx of Held-MNTB principal cell synapse are expected to cause significant deviations from the holding potential in single-electrode voltage-clamp experiments. With the approximately linearly conducting AMPA receptor-mediated EPSCs (Forsythe and Barnes-Davies, 1993), $R_{\mathrm{s}}$ errors should lead to an underestimation of EPSC peak amplitudes and EPSC variance. To minimize these errors, the following measures were taken. First, under conditions of high release probability $\left(\left[\mathrm{Ca}^{2+}\right] \geq 10 \mathrm{mM}\right)$, experiments were performed in the presence of AMPAR blockers to keep EPSC amplitudes $<10 \mathrm{nA}$ (see Figs. 4-7). Second, the electronic $R_{\mathrm{s}}$ compensation of the amplifier was set such that the uncompensated fraction of $R_{\mathrm{s}}$ did not exceed $3 \mathrm{M} \Omega$, and recordings with measured $R_{\mathrm{s}}$ of $>10 \mathrm{M} \Omega$ were excluded from the analysis. Third, the actual value of $R_{\mathrm{s}}$ was measured during interstimulus intervals by using the automatic capacitance cancellation of the EPC-9 amplifier. This provided a value of $R_{\mathrm{s}}$ for each stimulus train during the experiment (see Fig. $6 B$ ). The off-line analysis then started by recalculating the expected EPSC waveform from the digitized trace (see Fig. $6 A$ ) (see also Traynelis, 1998), by using the uncompensated fraction of $R_{\mathrm{s}}$ available for each stimulus train and assuming a reversal potential of +10 $\mathrm{mV}$ for EPSCs. To ensure that there was not a large amount of additional variance caused by this compensation, the increase in EPSC amplitude was limited to $30 \%$; cells exceeding this limit were excluded from further analysis. Note that all displayed traces have undergone off-line compensation. Peak EPSC amplitudes were measured with a first-derivative threshold detection algorithm. When EPSCs summated (see Fig. 2), an extrapolation of double-exponential fits to the decaying phase of previous EPSCs was used to subtract the current contribution of previous EPSCs. Analysis was done with IGOR Pro (Wavemetrics, Lake Oswego, OR). Statistical significance was assessed with Student's $t$ test, and results were expressed as mean \pm SD unless noted otherwise.

Detection of spontaneous miniature EPSCs. For analyzing spontaneous miniature EPSCs (mEPSCs), $10 \mathrm{sec}$ stretches of data were recorded between stimulations. Current signals were low-pass filtered at $6 \mathrm{kHz}$ and sampled at $20 \mathrm{kHz}$. Detection of mEPSC was done with a first-order derivative algorithm, applied to traces after additional digital low-pass filtering at $2 \mathrm{kHz}$. Detected events were then extracted from the unprocessed traces and aligned to the $50 \%$ rising point for averaging.

Variance versus mean analysis of synaptic currents. We developed an approach that allows us to estimate quantal parameters during nonstationary conditions of short-term plasticity. Trains of stimuli were applied to induce synaptic depression (see Figs. 1, 2, 4, 5), and the depressing trains were repeated in regular intervals of either 20 or $25 \mathrm{sec}$ to allow for recovery from synaptic depression. Based on the binomial model for synaptic transmission (Quastel, 1997), after a stimulus $i$, quanta add up linearly to the total average current $I$, so this amplitude can be noted as:

$$
I_{\mathrm{i}}=N q_{\mathrm{i}} p_{\mathrm{i}}
$$

where $i$ indicates that $q$ and $p$ do not have to be the same for all stimuli $i$. In fact, short-term plasticity is likely to change these parameters.

In Equation 1, $N$ denotes the number of independent "release sites" at which quantal release events can take place. Unfortunately, the term release site resulting from the binomial definition (Quastel, 1997) does not contain an obvious structural correlate, such as a morphologically defined "active zone." Here, we will use the term active zone as defined by ultrastructural analysis (Harris and Sultan, 1995; Schikorski and Stevens, 1997; Lübke et al., 2000), and refer to $N$ in Equations 1-5 as the "binomial parameter $N$ ", which is not necessarily equal to the number of active zones (see Discussion).

The nonstationary variant of EPSC variance-mean analysis is based on the idea that in repetitively applied stimulus trains, corresponding stimuli have identical $q_{i}$ and $p_{i}$. The variance, $V a r_{i}$, between stimuli with the same $q_{i}$ and $p_{i}$ can then be written as (Quastel, 1997; Scheuss and Neher, 2001):

$$
V a r_{\mathrm{i}}=N q_{\mathrm{i}}^{2} p_{\mathrm{i}}\left(1-p_{\mathrm{i}}\right)
$$

or, in terms of average current

$$
\operatorname{Var}_{\mathrm{i}}=q_{\mathrm{i}} I_{\mathrm{i}}-\frac{1}{N} I_{i}^{2} .
$$

Under conditions of constant, uniform $q$, the EPSC variance-mean relationship should fall on a parabola (Silver et al., 1998). However, use-dependent changes in quantal size $q$ are expected to lead to a distortion of the parabolic relationship, as observed experimentally (see Figs. 5-7) (see also Oleskevich et al., 2000).

For analysis, a suitable stretch of repetitively applied trains with sufficiently stable whole-cell parameters $\left(R_{\mathrm{s}}\right.$ and leak current) was identified. This usually corresponded to the first $15-20 \mathrm{~min}$ of whole-cell recording. The variance $\operatorname{Var}_{i}$ for all responses at stimulus $i$ was calculated by taking the variance of small, overlapping "windows" with sizes of 2-3 consecutive responses and averaging variance values over as many windows as possible. This procedure minimizes the influence of long-term trends (see Fig. $4 A$ ) on the variance estimate (Heinemann and Conti, 1992). The resulting mean variance for each stimulus is shown as mean \pm SEM.

Plots of variance-mean data were fitted with Equation 3 (see Figs. 5-7); or else, slopes of variance-mean plots were estimated by linear regression (see Figs. 1,2). The resulting values of quantal size and binomial parameter $N$ are denoted as $q^{*}$ and $N^{*}$, respectively. These estimates were subsequently corrected for the variability of mEPSC amplitude distributions, to give corrected quantal sizes $q$ and binomial parameters $N$, according to (Brown et al., 1976; Silver et al., 1998; Scheuss and Neher, 2001):

$$
q=q^{*}\left(1+C V^{2}\right)^{-1}
$$

and

$$
N=N^{*}\left(1+W \cdot C V^{2}\right)
$$

Here, CV denotes the average coefficient of variation ( $\mathrm{SD} / \mathrm{mean})$ measured from mEPSC distributions (see Fig. $3 B$ ). The symbol $W$ represents the fraction of quantal variance that is caused by variability between different active zones (Frerking and Wilson, 1996). Note that the contribution of channel gating to the peak EPSC variance (Silver et al., 1996) would show up as a (small) contribution to the $\mathrm{CV}$ within each active zone. Because at the calyx of Held synapse, the source of variability in mEPSC amplitude distributions is not known, we assumed $W$ to be 0.5 .

The derivation of Equation 3 assumes a uniform value of release probability $p$ between different active zones. It has been shown, however, that $p$ is heterogeneous between active zones (Rosenmund et al., 1993; Murthy et al., 1997). A similar term $\left(1+\mathrm{CV}^{2}\right)$ could be applied to correct the estimate of $N$ for the variation of $p$ between active zones (Brown et al., 1976). Note that for a $p$ distribution with $\mathrm{CV} \approx 50 \%$ (Murthy et al., 1997), $N$ would have been underestimated by $\approx 25 \%$.

EPSC variance with multivesicular release and saturable postsynaptic receptors. For the model calculations in Figure 9, we assumed that each active zone contained a fixed number $(M)$ of vesicles that can be released by a presynaptic action potential with probability $p$. For simplicity, 
variability of quantal parameters $p$ and $q$ between active zones was not included in the model calculations shown in Figure 9. Vesicles at a given active zone were considered to release transmitter onto a common pool of postsynaptic receptors. The fraction of the receptor pool that is bound after the release of a single vesicle is denoted $f$. For a second vesicle released shortly $(<0.3 \mathrm{msec})$ after the first one, the fraction of available postsynaptic receptors will be reduced to $1-f$. The current at an active zone, $i_{a z}$, as a function of the number of released vesicles, $m$, can then be obtained as (Auger et al., 1998):

$$
i_{\mathrm{az}}(m)=i_{\max }\left(1-(1-f)^{\mathrm{m}}\right),
$$

where the current at full receptor saturation is given by $i_{\text {max }}=i_{1 v e s} / f$, with $i_{\text {lves }}$, the current caused by the fusion of a single vesicle, set to $40 \mathrm{pA}$. To calculate the synaptic current $I$ for a large number of active zones $N_{a z}$ as a function of release probability $p$, one can first calculate the expected average current at an active zone, $\left\langle i_{a z}(p)\right\rangle$, by summing over the binomial probability of releasing $m=0,1,2, \ldots, M$ vesicles (Matveev and Wang, 2000):

$$
\left\langle i_{\mathrm{az}}(p)\right\rangle=\sum_{m=0}^{\mathrm{M}}\left(\begin{array}{c}
\mathrm{M} \\
\mathrm{m}
\end{array}\right) p^{\mathrm{m}}(1-p)^{\mathrm{M}-\mathrm{m}} i_{\mathrm{az}}(m)=i_{\max }\left[1-(1-p \cdot f)^{\mathrm{M}}\right] .
$$

In analogy, the average number of vesicles released at an active zone, $<m_{a z}(p)>$, can be calculated. The quantal size per released vesicle at an active zone, abbreviated as $q_{v e s}$ in Figure $9 B$, was obtained as $q_{v e s}=$ $<i_{a z}(p)>/<m_{a z}(p)>$.

Multiplying $<i_{a z}(p)>$ by the number of active zones $N_{a z}$ gives the expected average synaptic current as a function of $p$ :

$$
\langle I(p)\rangle=N_{\mathrm{az}}\left\langle i_{\mathrm{az}}(p)\right\rangle .
$$

$N_{a z}$ was scaled so that the model produced a fixed value $I_{\max }$ at $p=1$. Thus, the number active zones $N_{a z}$ needed to generate $I_{\max }$ at $p=1$ becomes a function of postsynaptic receptor occupancy, for the case of $M>1$ (see Fig. 9D).

The EPSC variance as a function of $p$ is given by:

$$
\operatorname{Var}(p)=N_{\mathrm{az}}\left[\left\langle i_{\mathrm{az}}^{2}\right\rangle-\left\langle i_{\mathrm{az}}\right\rangle^{2}\right]
$$

Similar to the corresponding expression for the current (Eq. 7), EPSC variance can be shown to be equal to (V. Scheuss, personal communication):

$$
\operatorname{Var}(p)=N_{\mathrm{az}} i_{\max }^{2}\left[(1+p \cdot f(f-2))^{M}-(1-p \cdot f)^{2 M}\right] .
$$

For the plot in Figure 9C, variance Var as calculated from Equation 10 was plotted versus $I$ as calculated from Equations 7 and 8.

\section{RESULTS}

\section{Variance of EPSCs during $10 \mathrm{~Hz}$ depression}

At the calyx of Held-MNTB principal cell synapse, trains of stimuli at frequencies of $0.2-10 \mathrm{~Hz}$ induce noticeable synaptic depression, which has been proposed to result from a progressive decrease in the number of released quanta (von Gersdorff et al., 1997; Weis et al., 1999; Takahashi et al., 2000). To verify the proposed mechanism by EPSC variance-mean analysis, postsynaptic cells were voltage-clamped at $-80 \mathrm{mV}$, and EPSCs were evoked in $10 \mathrm{~Hz}$ trains repeated every $20 \mathrm{sec}$. During this interval, recovery from depression should be completed by $>90 \%$ (von Gersdorff et al., 1997). For each stimulus number within the 10 $\mathrm{Hz}$ trains, the mean EPSC amplitude and the variance of EPSC amplitudes were analyzed for a large number (30-135) of successive trains.

Figure 1 shows the results from a representative cell. Here, $n=$ 120 trains could be analyzed. The plot of average EPSC amplitudes versus stimulus number (Fig. $1 C$ ) reveals that EPSC amplitudes decreased monotonically with stimulus number. At the eighth stimulus, EPSC amplitudes were reduced to $36.7 \pm 13.1 \%$ ( $n=8$ cells) of the initial amplitude, in good agreement with previous findings (von Gersdorff et al., 1997). When the variance
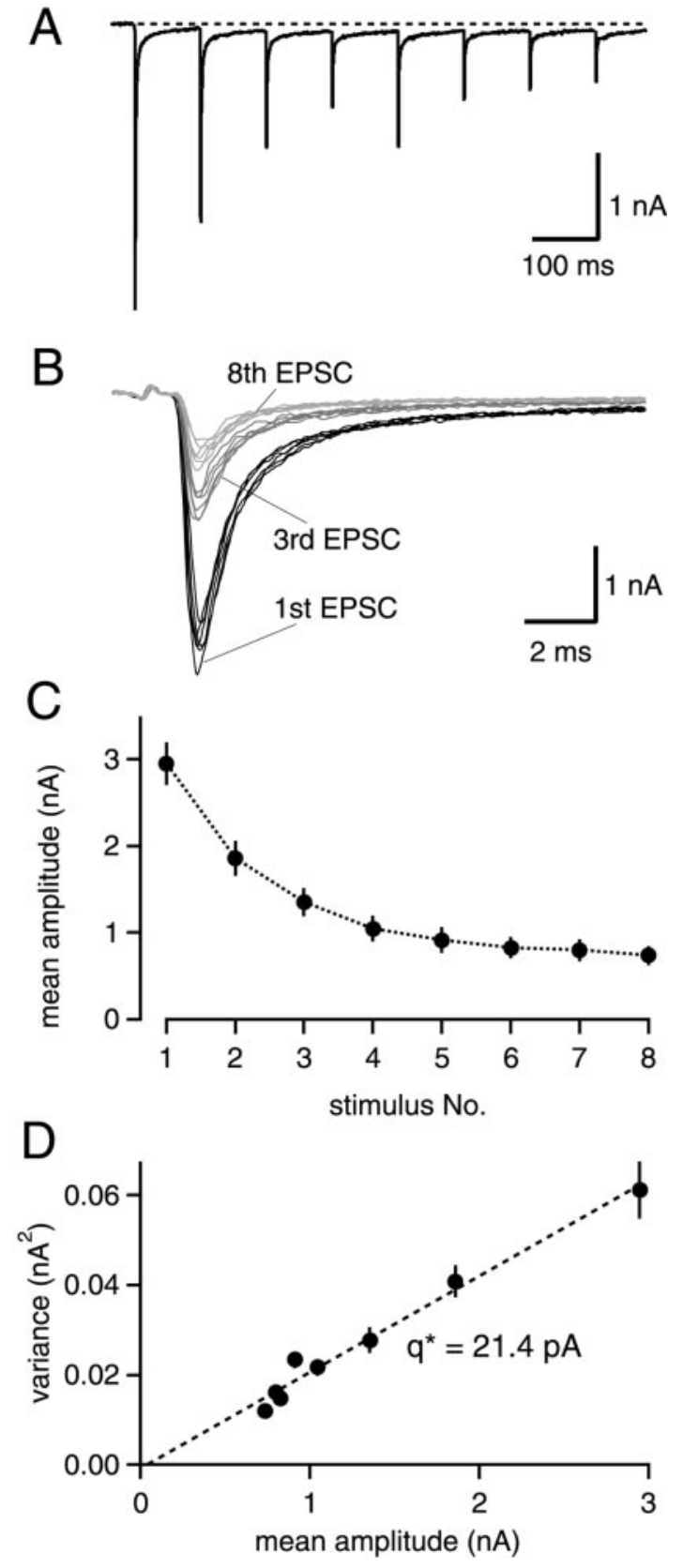

Figure 1. Nonstationary EPSC variance-mean analysis during $10 \mathrm{~Hz}$ trains. $A$, A single postsynaptic current trace in response to a $10 \mathrm{~Hz}$ stimulus train. $B$, The first, third and eighth EPSC of six consecutive stimulus trains at higher time resolution. $C$, Mean EPSC amplitudes and their SDs for 125 consecutive trains as a function of stimulus number. $D$, Plot of EPSC variance as a function of mean EPSC amplitudes, for the same data set as shown in $C$. Linear regression yields a slope of $21.4 \mathrm{pA}$ in this example.

between EPSCs in successive trains was plotted versus the corresponding average EPSC amplitude, a linear relationship was apparent (Fig. 1D). Such a linear relationship was observed in $n=8$ of 9 cells.

A similar series of experiments was done in the presence of 100 $\mu \mathrm{M}$ cyclothiazide (CTZ) to exclude the possibility that postsynaptic receptor desensitization might influence the variance-mean relationship. Cyclothiazide (CTZ) is known to slow the desensitization of AMPA-type glutamate receptors by varying degrees, 

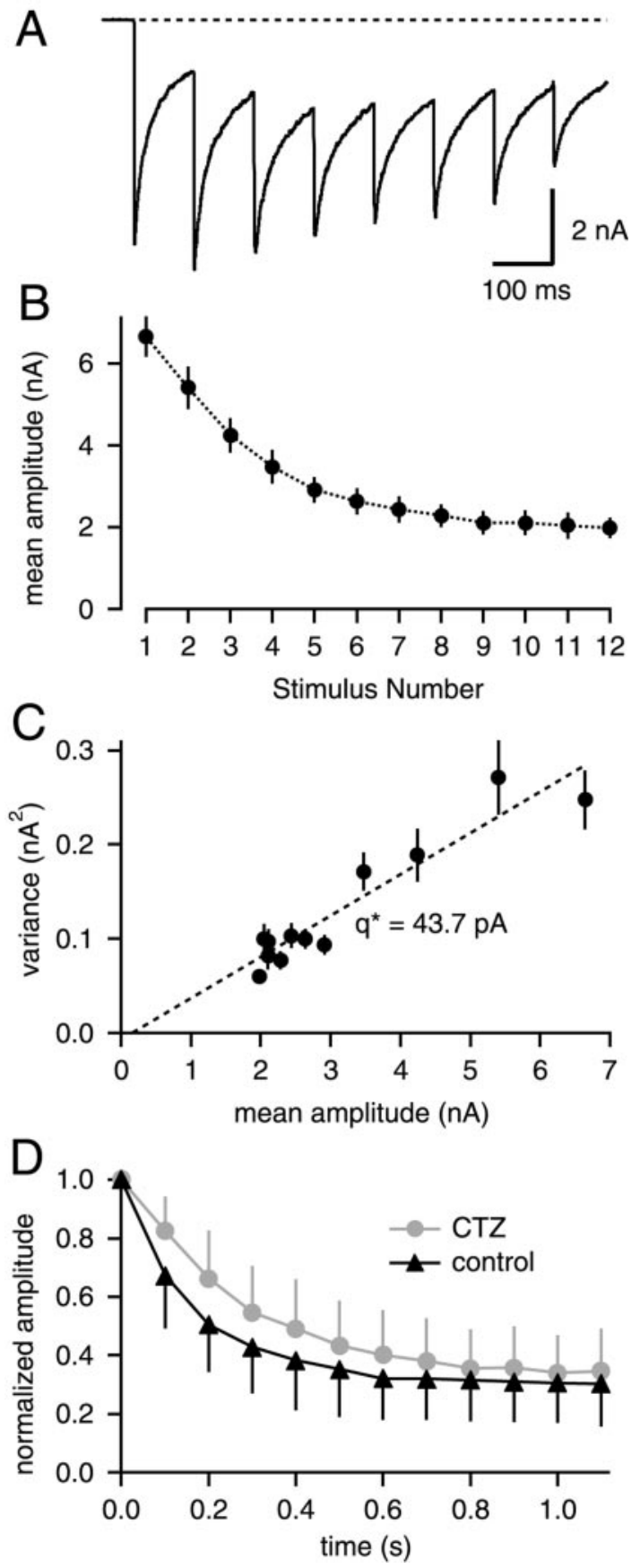

Figure 2. EPSC variance-mean analysis during $10 \mathrm{~Hz}$ stimulation in the presence of CTZ. $A$, EPSCs in response to a $10 \mathrm{~Hz}$ train in the presence of $100 \mu \mathrm{M}$ CTZ. $B$, Mean \pm SD of EPSC amplitudes in the presence of CTZ, averaged for 65 consecutive trains. $C$, The resulting EPSC variance-mean plot, fitted by linear regression with a slope of $43.7 \mathrm{pA}$. Data in $A-C$ are from the same cell. $D$, Average depression with $10 \mathrm{~Hz}$ trains under control conditions, and with $100 \mu \mathrm{M}$ CTZ. In each cell $(n=7)$, depression was first measured under control, followed by measurements with CTZ. EPSC amplitudes were normalized to the first amplitude to obtain average time courses of depression.

depending on the subunit composition of AMPA receptors (Partin et al., 1994). EPSCs recorded in the presence of $100 \mu \mathrm{M} \mathrm{CTZ}$ showed prolonged decay times (compare Figs. $1 A, 2 A$ ), and the EPSC decay was not complete before the subsequent stimulus in $10 \mathrm{~Hz}$ trains (Fig. 2A). Peak EPSC amplitudes were therefore analyzed by subtracting the current remaining from previous
EPSCs (see Material and Methods). Again, a linear relationship in the EPSC variance-mean plot was found in $n=4$ of 5 cells (Fig. 2C). Average synaptic depression, when normalized to the first EPSC amplitude in a train, was slightly slowed in the presence of CTZ (Fig. 2D), indicating that AMPAR desensitization might contribute a small amount of synaptic depression at a stimulus frequency of $10 \mathrm{~Hz}$.

The finding of linear relationships in the EPSC variance-mean plots obtained from $10 \mathrm{~Hz}$ stimulus trains is unexpected, because release probability at the calyx of Held synapse has been reported to be close to $90 \%$ (Chuhma and Ohmori, 1998). Based on a binomial model for synaptic transmission, one should therefore expect a nearly parabolic relationship (Silver et al., 1998). On the other hand, it has been shown previously that increasing the extracellular $\left[\mathrm{Ca}^{2+}\right]$ can potentiate EPSC amplitudes at the calyx of Held synapse up to fivefold (Schneggenburger et al., 1999). This implies that release probability under conditions of "normal" extracellular $\left[\mathrm{Ca}^{2+}\right](2 \mathrm{mM})$ must be low, compatible with a linear relationship in the EPSC variance-mean plot (Figs. $1 D, 2 C$ ). If this explanation is correct, then the slope of the variance-mean plots should reflect the quantal size during evoked synaptic transmission. To verify this prediction, we measured spontaneously occurring mEPSCs and compared their mean amplitudes to the slopes of the variance-mean plots (Fig. 3).

\section{Quantal size from miniature EPSC amplitude distributions}

Spontaneous mEPSCs were measured between stimulus intervals, either under control conditions $(n=12$ cells) or in the presence of $100 \mu \mathrm{M} \mathrm{CTZ} \mathrm{(} n=8$ cells) (Fig. $3 A$ ). For each cell, a histogram of mEPSC amplitudes was obtained. This was used to calculate mean and coefficient of variation (CV) (Fig. 3B). A histogram of all means is shown in Figure $3 C$. Under control conditions, the mean mEPSC amplitude across cells was $30.9 \pm$ $12.0 \mathrm{pA}$, a value comparing favorably to previous reports (Chuhma and Ohmori, 1998; Schneggenburger et al., 1999). With CTZ, the mEPSC amplitude averaged over all cells was $38.0 \pm$ $10.5 \mathrm{pA}(n=8)$.

The CV calculated from each mEPSC amplitude distribution represents the intrinsic variability of the quantal currents for a given cell. The average $\mathrm{CV}$ for mEPSC distributions in control conditions and with $100 \mu \mathrm{M} \mathrm{CTZ}$ was $0.58 \pm 0.10$ and $0.48 \pm 0.06$, respectively. The $\mathrm{CV}$ was used to correct the slopes $\left(q^{*}\right)$ obtained from the variance-mean plots, giving quantal sizes $q$ (Eq. 4). The values for $q$ derived from this analysis are shown as histograms in Figure 3D. The mean values across cells recorded at a holding potential of $-80 \mathrm{mV}$ were $25.1 \pm 9.6$ and $30.1 \pm 5.8 \mathrm{pA}$ under control conditions and with $100 \mu \mathrm{M}$ CTZ, respectively. On average, the values for $q$ estimated from EPSC variance-mean plots were slightly smaller than, but still in good agreement with the means of the mEPSC amplitude distributions.

\section{EPSC variance analysis at high initial release probability}

We hypothesize that the linear form of the EPSC variance-mean plots reflects a low initial release probability $p$ in the experiments of Figures 1 and 2. We therefore sought to increase the initial release probability strongly by elevating $\left[\mathrm{Ca}^{2+}\right]$. Increasing $\left[\mathrm{Ca}^{2+}\right]$ from 2 to 10 or $15 \mathrm{~mm}$ induced a fivefold to sevenfold potentiation of EPSCs (see Fig. $8 C$ for summary), in good agreement with previous results (Schneggenburger et al., 1999). The experiments were performed in the presence of submaximal concentrations of 

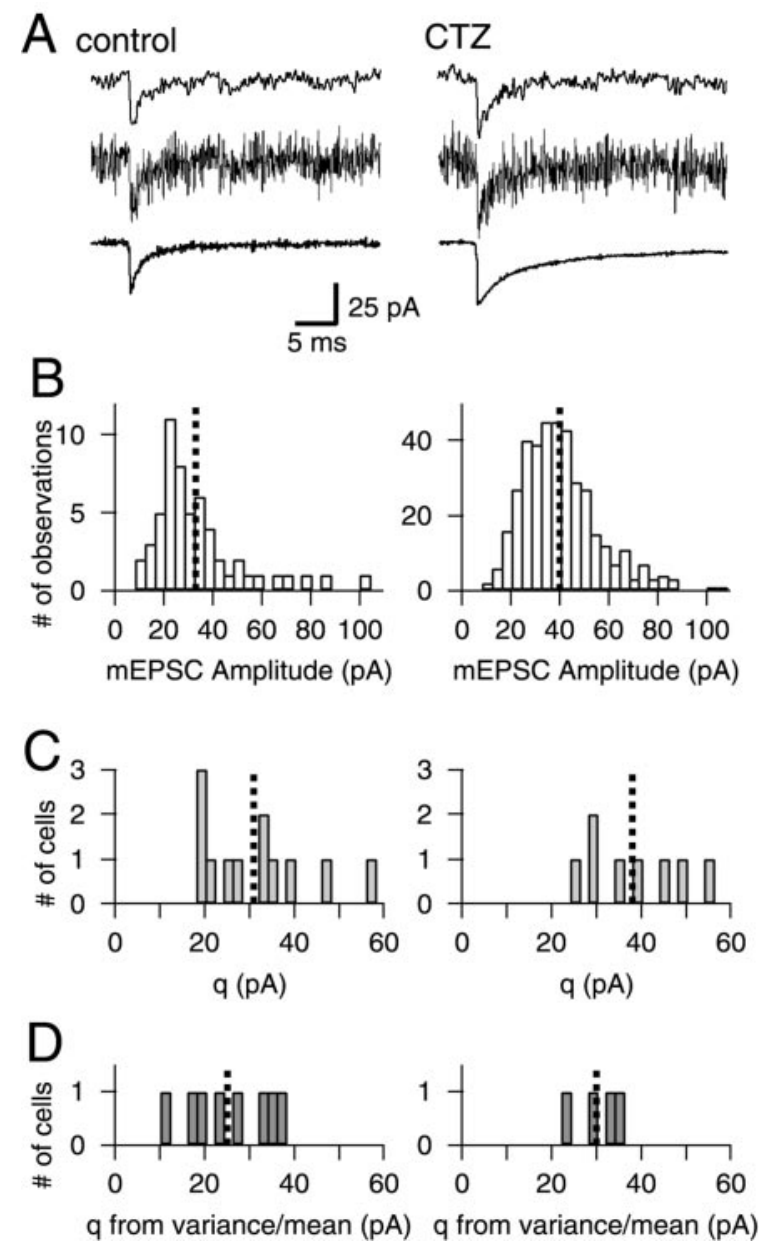

Figure 3. The mean of mEPSC amplitude distributions matches the quantal size $q$ determined from the slope of EPSC variance-mean plots. $A$, Spontaneous mEPSCs under control conditions (left $)$ and in the presence of CTZ (right). Top and middle traces represent single events filtered at 2 and $6 \mathrm{kHz}$, respectively. Bottom trace, Averages of events filtered at 6 kHz. $B$, mEPSC amplitude distributions for the same cell as shown in $A$. The mean amplitude (dotted line) increased from $32.9 \mathrm{pA}$ (55 events) to $39.8 \mathrm{pA}$ in CTZ (386 events). $C$, Histograms of the means obtained from mEPSC amplitude distributions. Left, Control, $n=12$ cells, mean $=$ $30.9 \pm 12.0 \mathrm{pA}$; right, CTZ, $n=8$ cells, mean $=38.0 \pm 10.5 \mathrm{pA} . D$, Quantal size from EPSC variance-mean analysis obtained with $10 \mathrm{~Hz}$ stimulus trains at $2 \mathrm{mM}\left[\mathrm{Ca}^{2+}\right]$ (Figs. 1,2), corrected for the $\mathrm{CV}$ of mEPSC distributions for control and CTZ conditions (Eq. 4). Left, Control, $n=8$ cells, mean $=25.1 \pm 9.6 \mathrm{pA}$; right, CTZ, $n=4$ cells, mean $=30.1 \pm 5.8 \mathrm{pA}$. In $B-D$, the means of the distributions are indicated by vertical dotted lines.

AMPAR blockers to minimize series resistance errors related to the large conductance change during EPSCs (see Materials and Methods). In the first series of experiments, 70 nм NBQX was used, which, at $2 \mathrm{~mm}\left[\mathrm{Ca}^{2+}\right]$, reduced the EPSCs to $43.6 \pm 10.4 \%$ ( $n=6$ cells) of their initial amplitude (see Figs. $4 A, 8 A$ ).

Because synaptic depression becomes more pronounced under conditions of high release probability, we also changed the stimulus pattern. Instead of using trains with uniform interstimulus intervals, 12 stimuli with interstimulus intervals initially as long as $2.5 \mathrm{sec}$ but becoming progressively shorter-down to $7 \mathrm{msec}-$ were used (Fig. $4 C$ ). This allowed us to probe a wide range of EPSC amplitudes with almost constant amplitude decrements. Trains were given every $25 \mathrm{sec}$, which should allow for sufficient recovery from synaptic depression.
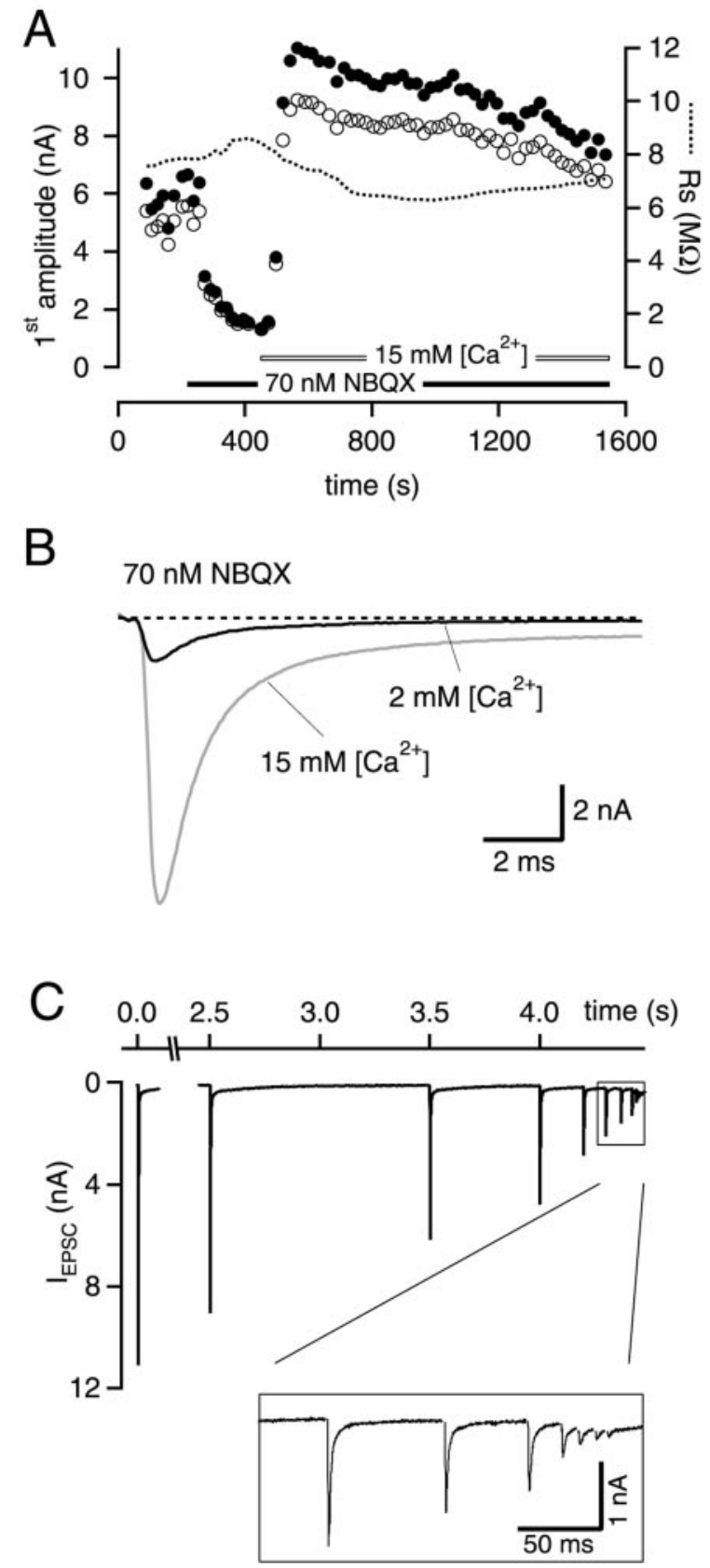

Figure 4. Design of the experiments with elevated extracellular $\left[\mathrm{Ca}^{2+}\right]$. $A$, Stability plot of amplitudes of first EPSCs in the train and series resistance $R_{\mathrm{s}}$ during a typical experiment. Open circles denote EPSC amplitudes measured from digitized EPSC traces. Filled circles represent EPSC amplitudes measured from traces that have undergone an additional off-line compensation of voltage-clamp errors (see Materials and Methods). Time 0 refers to the start of whole-cell recording. In these experiments, part of the EPSCs were first blocked by a competitive antagonist (NBQX in this case). In the presence of the antagonist, the $\left[\mathrm{Ca}^{2+}\right]$ in the bath was then increased. $B$, Sample traces for EPSCs recorded at two different $\left[\mathrm{Ca}^{2+}\right]$ in the presence of NBQX. $C$, EPSCs in response to the stimulus trains used for these experiments, recorded with $15 \mathrm{~mm}\left[\mathrm{Ca}^{2+}\right]$ and $70 \mathrm{~nm}$ NBQX. Stimulus artifacts have been removed for clarity. Note the constant decrement of EPSC amplitudes that was achieved by this stimulation protocol. Data in $A-C$ are from the same experiment. 


\begin{tabular}{|c|c|c|c|c|c|}
\hline Cell & $\begin{array}{l}\text { Ionic condi- } \\
\text { tions (mM) }\end{array}$ & $\begin{array}{l}\text { Fit of } \\
\text { parabola }\end{array}$ & $N$ & $q(\mathrm{pA})$ & $\begin{array}{l}q_{\text {initial slope }} \\
(\mathrm{pA})\end{array}$ \\
\hline Nov03A & $10 \mathrm{Ca}, 1 \mathrm{Mg}$ & $+($ sat $)$ & 467 & 15.6 & 7.0 \\
\hline Dec17B & & + & 290 & 17.9 & 6.3 \\
\hline Feb19A & & + & 675 & 15.2 & 6.4 \\
\hline Feb19B & & - & & & 2.8 \\
\hline Mar04A & & + & 130 & 30.9 & 4.6 \\
\hline Mar04B & & $+($ sat $)$ & 845 & 7.5 & 4.4 \\
\hline Mar08A & $15 \mathrm{Ca}, 0 \mathrm{Mg}$ & - & & & 8.7 \\
\hline Mar08B & & + & 510 & 21.7 & 6.0 \\
\hline Mar10A & & $+($ sat $)$ & 576 & 9.4 & 3.1 \\
\hline Mar11B & & + & 1995 & 6.9 & 2.6 \\
\hline Average $\pm \mathrm{SD}$ & & & $686 \pm 573$ & $15.6 \pm 8.1$ & $5.2 \pm 2.0$ \\
\hline
\end{tabular}

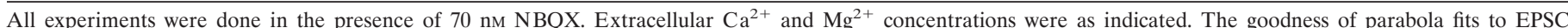

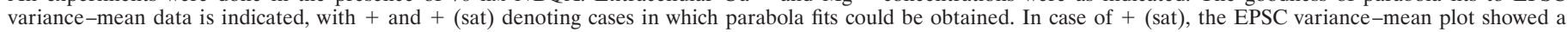

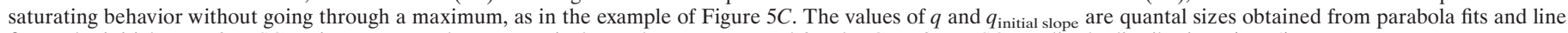
fits to the initial part of EPSC variance-mean plots, respectively. Both were corrected for the CV of mEPSC amplitude distributions (Eq. 4).

We changed $\left[\mathrm{Ca}^{2+}\right]$ from 2 to $10 \mathrm{mM}$ in six cells and to $15 \mathrm{mM}$ with no added $\mathrm{Mg}^{2+}$ in another four cells, with similar results (Table 1). In the variance-mean analysis, 5 of 10 cells showed a variance of the first and largest EPSC that was $>30 \%$ lower than the second and sometimes also the third one (Fig. 5B). According to the binomial model in its simplest form (see Fig. 9C, dotted line), this behavior is expected when release probability during the first EPSC is $>0.5$. In another three cells, the variance of the first EPSC was not significantly lower than that of the second one, but of approximately equal size (Fig. $5 C$, Table 1). Thus, the deviation of the EPSC variance-mean plot from a line was obvious in most of the cells studied under conditions of high initial release probability (Table 1). On the other hand, we never observed that the variance of the first EPSC - representing the highest release probability - was smaller than $46 \%$ of that of the second or third EPSC. When expressed as CV, the variability of the first EPSC under these conditions was found to be $0.047 \pm$ 0.022 .

To test whether possible inaccuracies in the $R_{\mathrm{s}}$ estimate (see Material and Methods) would affect the results, we performed the analysis in some cells with $R_{\mathrm{s}}$ arbitrarily set to 130,100 , and $70 \%$ of the measured value (Fig. 6). Qualitatively, the EPSC variancemean plot was not changed-a parabola could be fitted in all three cases (Fig. 6C). However, the $x$-axis intercept found by the parabola fit was quite sensitive to a change in the assumed $R_{\mathrm{s}}$. This shows that measuring $R_{\mathrm{s}}$ during the experiment, and the off-line correction of remaining $R_{\mathrm{s}}$ errors is important for estimating the parameter $N$ from EPSC variance-mean plots. Nevertheless, Figure $6 C$ also shows that the relative error of $N$ is smaller than that of the $R_{\mathrm{s}}$ estimate.

\section{Indications for a decreased quantal size}

A remarkable finding for the cells under high initial release probability was that the slope of the variance-mean plot close to zero-resulting from EPSCs late in the train-was shallower than expected from parabolic fits to the first three or four points (Fig. 5B,C). The deviation from the parabola was usually visible from stimulus number 5 on, which corresponds to EPSCs elicited with interstimulus intervals of $200 \mathrm{msec}$ or less (Fig. 4C). For the analysis, we fitted the first three or four data points with a parabola (Eq. 3; see Materials and Methods), constrained to pass through the origin of the graph (Fig. $5 B, C)$. The parameters of the parabola fit should reflect the binomial parameter $N$, as well as the quantal size $q$, during the first three or four EPSCs evoked in a stimulus train. The value for $q$ from such parabola fits, corrected for the CV of mEPSC distributions (Eq. 4), was found to be $15.6 \pm 8.1 \mathrm{pA}$ ( $n=8$ cells) (see Table 1 and Fig. $8 B$, left column). In addition, a line was fitted to the six to eight lowermost data points, to estimate the quantal size for the last six to eight EPSCs in the stimulus train. This value, denoted $q_{\text {initial slope }}$, was $5.2 \pm 2.0 \mathrm{pA}$, significantly lower than the quantal size $q$ early during stimulus trains (Table 1$)(p<0.01$; paired $t$ test). This indicates that at high release probability and with interstimulus intervals of $<200 \mathrm{msec}$, quantal size was reduced approximately threefold, probably because of desensitization of AMPARs (Trussell et al., 1993; Otis et al., 1996). Therefore, depression under these conditions is mediated, in part, by postsynaptic mechanisms.

Table 1 summarizes the results from the EPSC variance-mean analysis under high release probability conditions, obtained in the presence of the competitive antagonist, NBQX. Because NBQX does not dissociate significantly from AMPARs during the brief $(<1 \mathrm{msec})$ pulses of glutamate associated with fast synaptic transmission (Diamond and Jahr, 1997), the blocking efficiency of NBQX should be similar for conditions of low and high release probability, irrespective of possible changes in the effective glutamate concentration (Tong and Jahr, 1994). We therefore used the blocking efficiency of NBQX determined in each cell at $2 \mathrm{~mm}$ $\left[\mathrm{Ca}^{2+}\right]$ and the value of $q$ (see Fig. $8 A, B$, left columns, respectively) to calculate the quantal size $q_{\text {corr }}$ corresponding to the unblocked state of AMPARs, according to:

$$
q_{\mathrm{corr}}=q / r
$$

where $r$ denotes the remaining fraction of the EPSC amplitude after the blocking effect of NBQX had stabilized. This correction was done individually for each cell, and resulted in an average value $q_{\text {corr }}$ of $37.0 \pm 11.7 \mathrm{pA}(n=8$ cells $)$, a value that is in good agreement with the direct estimate of quantal size from mEPSC amplitude distributions (Fig. 3C).

\section{EPSC variance-mean analysis with a rapidly dissociating antagonist}

There is evidence that under conditions of high release probability, the effective transmitter concentration in the synaptic cleft is 

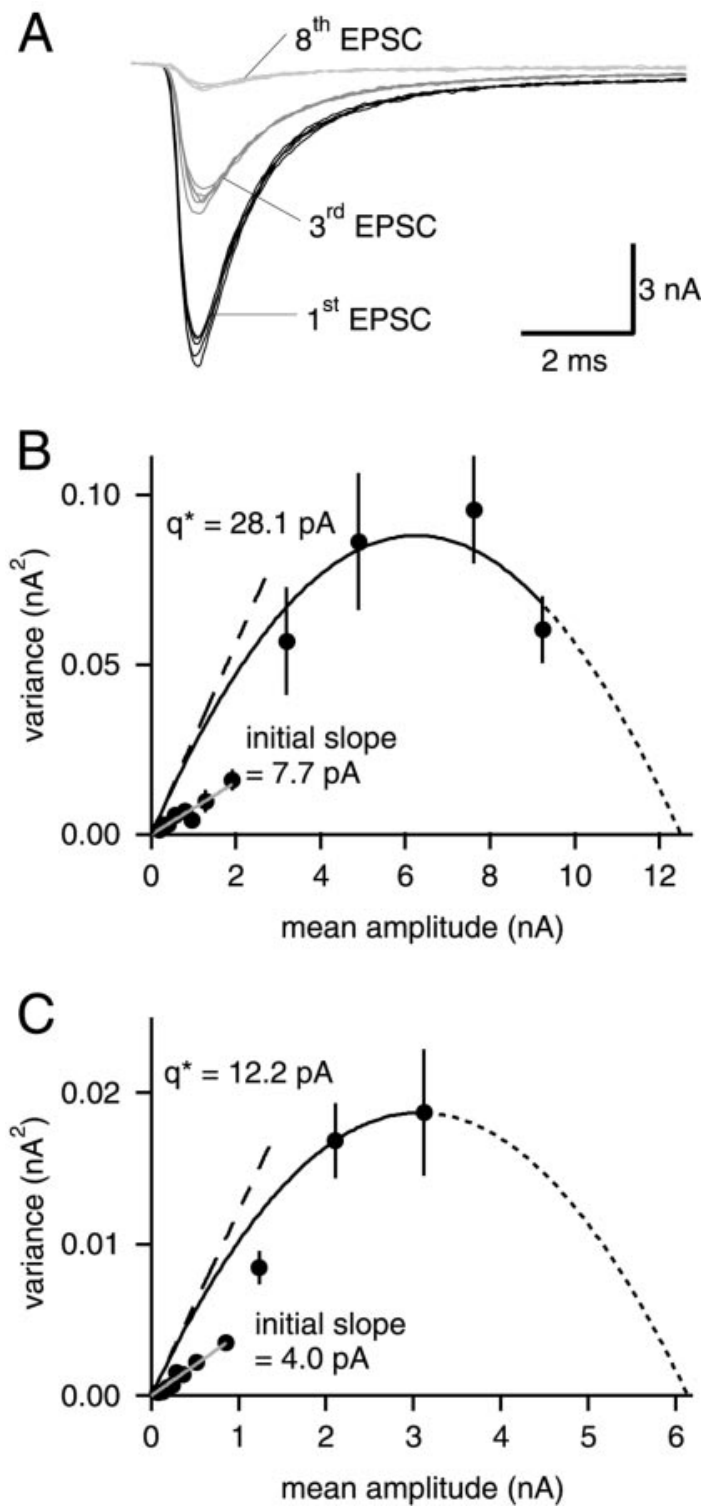

Figure 5. The EPSC variance-mean relationships at elevated $\left[\mathrm{Ca}^{2+}\right] \mathrm{can}$ be fitted with parabolas. $A$, EPSCs recorded in the presence of $15 \mathrm{~mm}$ $\left[\mathrm{Ca}^{2+}\right]$ and $70 \mathrm{~nm}$ NBQX. The first, third and eighth EPSC of five successive stimulus trains are shown. $B$, EPSC variance-mean relationship, obtained from analyzing 31 consecutive stimulus trains. Data points corresponding to the first four EPSCs in stimulus trains were fitted with a parabola, constrained to pass through the origin (solid line). Extrapolation of the parabola gave an $x$-axis intercept of $12.5 \mathrm{nA}$ (dotted line). The value of $q^{*}$ predicted by the parabola fit (28.1 pA; dashed line) differs clearly from the slope of a line fitted to the last eight data points $(7.7 \mathrm{pA}$; gray line). The values of $q^{*}$ and of the initial slope were used to calculate quantal sizes $q$ and $q_{\text {initial slope }}$ given in Table 1, by applying Equation 4 . Same cell as shown in $A$. $C$, Example of a cell in which the observed EPSC variance-mean relationship did not go through a maximum. The extrapolation of $x$-axis intercept toward large EPSCs has to be considered with caution; initial slopes, however, can be determined.

increased, possibly because of release from multiple vesicles at a given active zone ("multivesicular release"; Tong and Jahr, 1994; Auger et al., 1998). Also, under conditions of high release probability, repetitive stimulation can lead to a use-dependent decrease in quantal size, caused by AMPAR desensitization (Trussell et al., 1993; Otis et al., 1996). To verify the possible effects of saturation and desensitization of AMPA receptors on
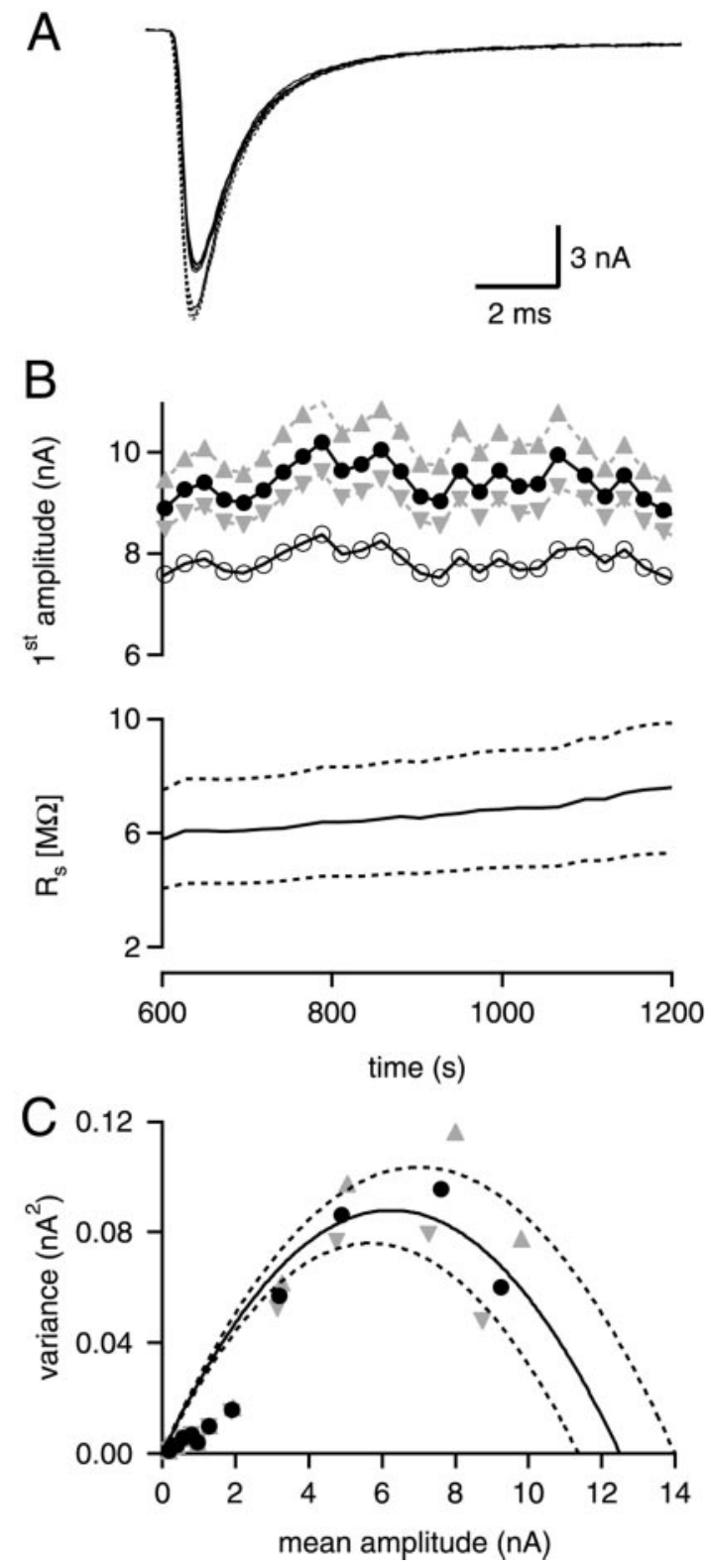

Figure 6. Possible effects of errors in the $R_{\mathrm{s}}$ estimate. $A$, Three consecutive EPSCs recorded in the presence of $15 \mathrm{~mm}\left[\mathrm{Ca}^{2+}\right], 70 \mathrm{~nm}$ NBQX. The traces shown as solid lines represent the recorded current signals. The traces shown as dotted lines have been obtained after off-line compensation of the remaining $R_{\mathrm{s}}$ error (Traynelis, 1998; see Material and Methods). In this example, the measured $R_{\mathrm{s}}$ was $6.1 \mathrm{M} \Omega$, which was compensated electronically by $70 \%$. The off-line compensation for the uncompensated fraction of $R_{\mathrm{S}}(1.8 \mathrm{M} \Omega)$ led to an increase by $19.3 \%$ of the EPSC amplitude. $B$, The bottom panel (solid line) shows $R_{\mathrm{s}}$ measured before each stimulus train (see Materials and Methods). Introducing a deliberate overestimate or underestimate of $R_{\mathrm{s}}$ by $\pm 30 \%$ (bottom panel, dotted lines) causes an error for the back-calculated EPSC amplitudes (top panel, gray triangles). Open circles denote measured EPSC amplitudes before off-line compensation. Filled circles and triangles show the EPSC amplitudes after off-line compensation, for $100 \%$, and for 70 and $130 \%$ of the measured $R_{\mathrm{s}}$ value, respectively. $C$, Effect of the $30 \%$ error in the $R_{\mathrm{s}}$ estimate on EPSC variance-mean plots (same cell as in Fig. $5 B$ ). Symbols have the same meaning as in $B$.

the parameters extracted from the EPSC variance-mean analysis, we performed additional experiments with $15 \mathrm{~mm}\left[\mathrm{Ca}^{2+}\right]$ and no added $\mathrm{Mg}^{2+}$, in the presence of either $0.5 \mathrm{~mm}$ kynurenic acid (kyn), or $2 \mathrm{~mm}$ kyn together with $0.1 \mathrm{~mm} \mathrm{CTZ} \mathrm{(Fig.} \mathrm{7,} \mathrm{Table} \mathrm{2).}$ 

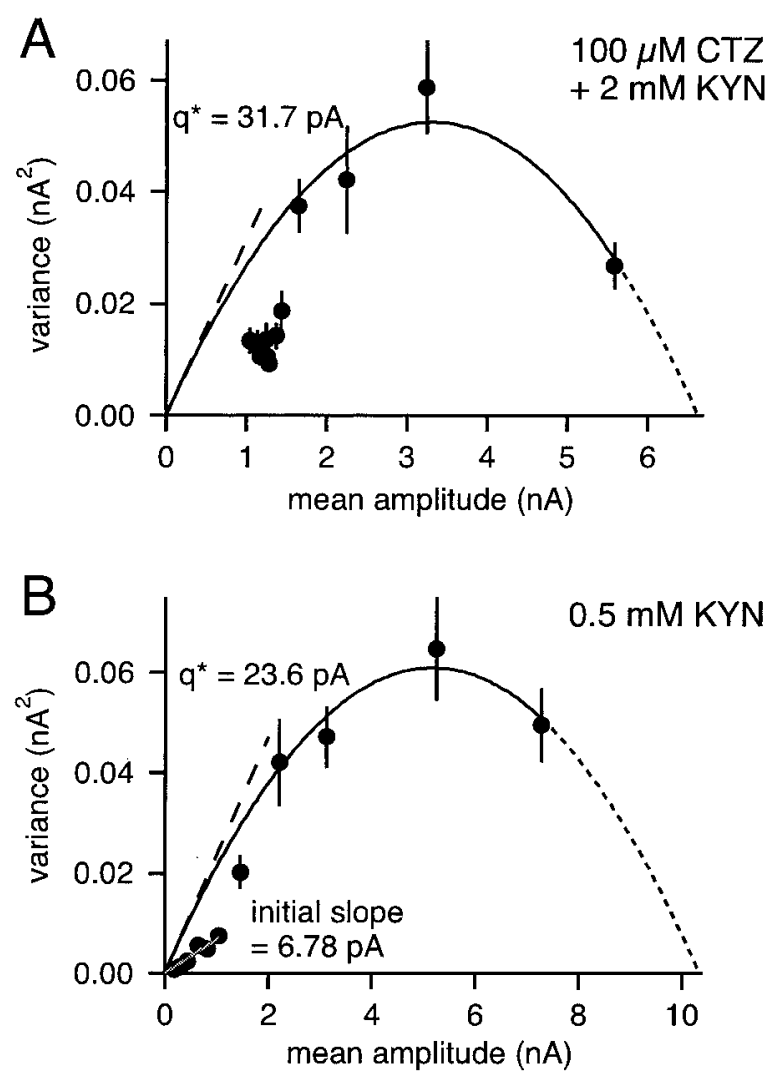

Figure 7. EPSC variance-mean relationships in the presence of kyn and kyn together with cyclothiazide. $A$, Variance-mean plot of one cell in the presence of $100 \mu \mathrm{M} \mathrm{CTZ}$ and $2 \mathrm{~mm}$ kyn. A parabola was fitted to the first four data points (solid line). The uncorrected quantal size $q^{*}$ found by the fit is indicated by the dashed line ( $31.7 \mathrm{pA}) . B$, Experiment in $0.5 \mathrm{~mm}$ kyn. Here, also the last seven data points could be fitted with a line (gray).

Kynurenic acid is a low-affinity, competitive antagonist with a fast unblocking time constant ( $\approx 400 \mu \mathrm{sec}$; Diamond and Jahr, 1997). It was used to block part of the postsynaptic conductance change (Fig. 8A). Because of its fast unblocking rate, it can be expected to minimize AMPAR saturation during conditions of high glutamate concentration. By combining kyn with CTZ in some of these experiments, we attempted to protect postsynaptic AMPA receptors against desensitization, as well as against saturation (Neher and Sakaba, 2001).

The results from experiments under these pharmacological conditions are shown in Figure 7 and are summarized in Table 2.
In seven of eight cells, the EPSC variance-mean plot showed a clear maximum. Thus, the variance of the largest EPSC was smaller than that of the second EPSC during depressing trains (Fig. 7), similar as observed with NBQX (Fig. 5, Table 1). The EPSC variance-mean data were analyzed as described above for the data obtained with NBQX. We found that the quantal size $q_{\text {initial slope }}$, calculated from the initial slope of the EPSC variance-mean plot, was again smaller than the value of $q$ derived from parabola fits to the 3-4 largest EPSC amplitudes, despite of the presence of CTZ (Table 2). More specifically, $q_{\text {initial slope }}$ was found to be $4.7 \pm 1.4$ pA $(n=7)$ (Table 2$)$, not significantly different from the value obtained with NBQX in the absence of CTZ. This might indicate that with the stimulus protocol used here (Fig. 4C), CTZ did not fully protect AMPARs from desensitization. Interestingly, MNTB principal neurons predominantly express AMPARs of the "flop" splice variant (Geiger et al., 1995). It has been shown in experiments with recombinantly expressed AMPARs that CTZ almost entirely blocks desensitization in the "flip" form, whereas in the flop form, the rate of desensitization with saturating concentrations of glutamate and CTZ is still quite high (time constant, $\approx 300$ msec; Partin et al., 1994). Therefore, the finding that CTZ did not prevent the reduction of $q$ late in trains (compare values of $q_{\text {initial slope }}$ in Tables 1 and 2) is compatible with the idea that a considerable amount of cumulative desensitization occurred in the presence of CTZ. This explanation is also supported by the finding that $\mathrm{CTZ}$ was more effective in preventing a quantal size reduction during shorter stimulus trains (<50 msec) (Scheuss and Neher, 2001).

Analysis of the EPSC variance-mean plots in the presence of $0.5 \mathrm{~mm}$ kyn revealed a quantal size $q$ of $16.9 \pm 1.95 \mathrm{pA}(n=4$ cells) (Table 2 , Fig. 8 B, right column), not significantly different to the one obtained with NBQX $(15.6 \pm 8.1 \mathrm{pA})$ (Table 1, Fig. $8 B$, left column). This is surprising because $0.5 \mathrm{~mm}$ kyn was more effective in blocking EPSCs at $2 \mathrm{~mm}\left[\mathrm{Ca}^{2+}\right]$ than was NBQX (Fig. 8A). The finding of similar quantal sizes $q$ at high $p$ despite a larger blocking efficiency of $0.5 \mathrm{~mm}$ kyn at $2 \mathrm{~mm}$ [Ca] (Fig. $8 A$ ) suggests that the blocking efficiency of kyn was reduced at high release probability. Because kyn is a rapidly dissociating antagonist (Diamond and Jahr, 1997), its reduced blocking efficiency indicates that the effective glutamate concentration was increased under high $p$ conditions (Tong and Jahr, 1994; see Discussion).

Figure 8C summarizes the degree of potentiation of EPSC peak amplitudes induced by changing the extracellular solution from $2 \mathrm{~mm}\left[\mathrm{Ca}^{2+}\right], 1 \mathrm{~mm}\left[\mathrm{Mg}^{2+}\right]$ to $15 \mathrm{~mm}\left[\mathrm{Ca}^{2+}\right]$ no added $\mathrm{Mg}^{2+}$. With kyn, an average EPSC potentiation of $6.9 \pm 1.3$-fold

Table 2. Results from EPSC variance-mean analysis in the presence of a rapidly dissociating AMPA receptor antagonist

\begin{tabular}{|c|c|c|c|c|c|}
\hline Cell & $\begin{array}{l}\text { Pharmacology } \\
(\mathrm{mM})\end{array}$ & $\begin{array}{l}\text { Fit of } \\
\text { parabola }\end{array}$ & $N$ & $q(\mathrm{pA})$ & $\begin{array}{l}q_{\text {initial slope }} \\
(\mathrm{pA})\end{array}$ \\
\hline Nov30A & $0.1 \mathrm{CTZ}, 2 \mathrm{kyn}$ & + & 240 & 24.5 & 7.5 \\
\hline Nov30B & & + & 393 & 35.7 & 3.8 \\
\hline Dec16A & & + & 597 & 12.9 & 4.0 \\
\hline Feb03A & & - & & & \\
\hline Jul20A & 0.5 kyn & + & 553 & 14.8 & 3.4 \\
\hline Jul20B & & + & 500 & 18.3 & 5.2 \\
\hline Jul21D & & + & 836 & 15.7 & 4.8 \\
\hline Aug02B & & + & 953 & 18.8 & 4.3 \\
\hline Average $\pm \mathrm{SD}$ & & & $582 \pm 246$ & $20.1 \pm 7.8$ & $4.7 \pm 1.4$ \\
\hline
\end{tabular}

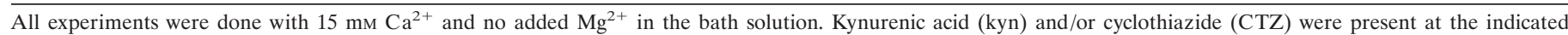
concentrations. All other symbols have the same meaning as in Table 1. 


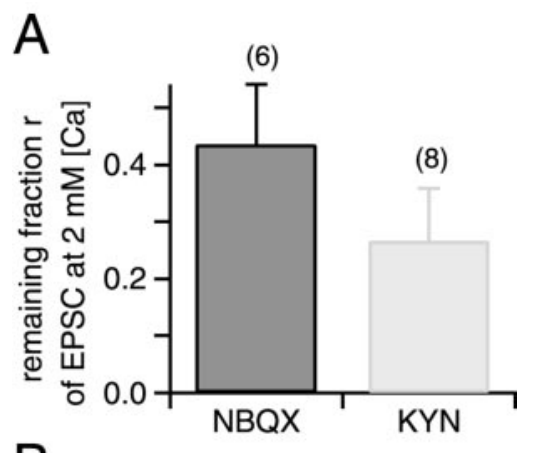

B
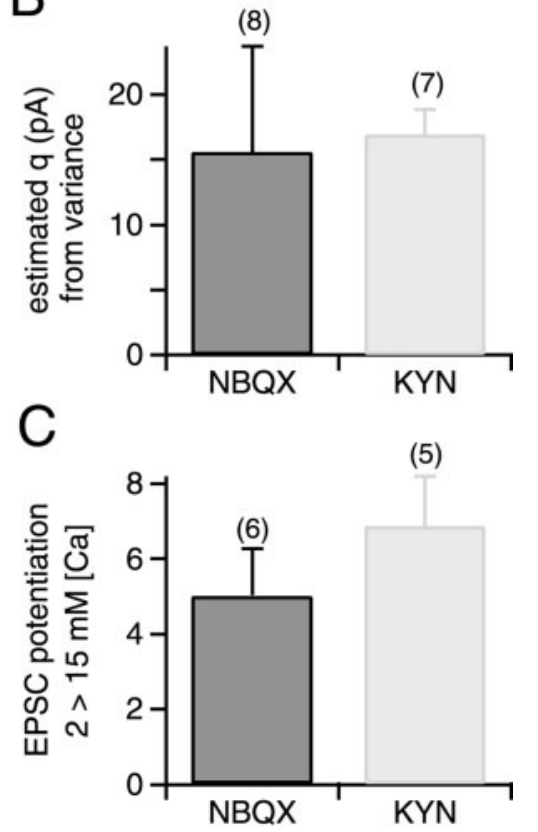

Figure 8. Summary of blocking efficiencies, estimated quantal sizes, and relative potentiation of EPSC amplitudes. $A$, Average values of the remaining fraction of peak EPSC amplitude $(r)$ after applying $70 \mathrm{~nm} \mathrm{NBQX}$ (left) or $0.5 \mathrm{~mm}$ kyn (right) in the presence of $2 \mathrm{mM}\left[\mathrm{Ca}^{2+}\right]$ and $1 \mathrm{mM}$ $\left[\mathrm{Mg}^{2+}\right]$ (see Fig. $4 A$ for an example). The number of cells examined for each condition is indicated. $B$, Average values of quantal size $q$, obtained from fitting parabolas to the first three or four data points in EPSC variance-mean plots (see Figs. 5, 7). Left panel, data obtained with $70 \mathrm{nM}$ NBQX (Fig. 5, Table 1); right panel, data obtained with $0.5 \mathrm{~mm}$ kyn (Fig. $7 B$, Table 2). $C$, Relative potentiation of EPSC amplitudes on switching the bath solution from $2 \mathrm{~mm}\left[\mathrm{Ca}^{2+}\right], 1 \mathrm{~mm}\left[\mathrm{Mg}^{2+}\right]$ to $15 \mathrm{~mm}\left[\mathrm{Ca}^{2+}\right]$, no added $\mathrm{Mg}^{2+}$. Left, data obtained with $70 \mathrm{~nm}$ NBQX; right, data obtained with $0.5 \mathrm{~mm}$ kyn. Note the slightly larger $(p<0.15)$ potentiation in the presence of the fast-off antagonist, kynurenic acid.

was observed. This value was slightly larger than the potentiation observed in the presence of $70 \mathrm{~nm}$ NBQX, which was $5.0 \pm$ 1.3-fold (Fig. 8C) $(p<0.15)$. Both values are in good agreement with previous results (Schneggenburger et al., 1999, their Fig. 3). The slightly stronger potentiation in the presence of the rapidly dissociating antagonist kyn (Fig. 8C, right column) again indicates that the effective glutamate concentration was increased under conditions of elevated release probability.

\section{DISCUSSION}

We have used nonstationary EPSC variance analysis to estimate the quantal parameters of transmission at the synapse formed between the calyx of Held axon terminals and MNTB principal cells. To do so, we made use of the finding that short-term synaptic depression can be induced many times throughout an experiment without an apparent run-down of the initial EPSC amplitude (von Gersdorff et al., 1997; Wang and Kaczmarek, 1998; Weis et al., 1999; Takahashi et al., 2000). Thus, short-term depression can be used to drive the synapse repetitively through different states of release probability. This approach can be seen as analogous to the nonstationary approach of noise analysis, in which single-channel parameters are estimated from nonstationary regimes of current traces (Sigworth, 1980).

In recent years, methods of EPSC variance analysis have been developed to extract quantal parameters of synaptic transmission at CNS synapses (Silver et al., 1998; Reid and Clements, 1999; Oleskevich et al., 2000) (for review, see Clements and Silver, 2000). In these studies, EPSCs were evoked at low frequencies during relatively long time intervals. The release probability was modulated by changing the extracellular $\left[\mathrm{Ca}^{2+}\right]$ between the recording episodes, and EPSC fluctuations were analyzed at various stationary states of synaptic strength. An advantage of the nonstationary approach used here is that during a relatively short time, a wide range of release probabilities can be probed. A disadvantage might be seen in the fact that a reduction in postsynaptic quantal size during synaptic depression will also lead to a reduction in EPSC amplitude (the measured quantity). This, however, should allow us to draw conclusions on the effective quantal size during the depressed state of a synapse. Indeed, we have obtained evidence for a reduced quantal size during synaptic depression under conditions of elevated release probability at short (<200 msec) interstimulus intervals (Figs. 5, 7).

\section{Quantal size during evoked synaptic transmission}

Applying nonstationary EPSC variance analysis with $10 \mathrm{~Hz}$ stimulus trains under conditions of "normal" release probability at 2 $\mathrm{mm}\left[\mathrm{Ca}^{2+}\right]$, we found a linear EPSC variance-mean relationship (Figs. 1, 2). Because EPSC amplitudes can be potentiated fivefold to sevenfold by switching to $15 \mathrm{~mm}\left[\mathrm{Ca}^{2+}\right], 0\left[\mathrm{Mg}^{2+}\right]$ (Fig. $8 C$ ) (Schneggenburger et al., 1999), we hypothesize that the linear relationship in the EPSC variance-mean plot at $2 \mathrm{~mm}^{\left[\mathrm{Ca}^{2+}\right]}$ represents the beginning of a parabola at low release probabilities. In agreement with this hypothesis, the quantal size $q$ calculated from the slope of the line fit agreed well with the mean of miniature EPSC distributions measured in this (Fig. 3) and other studies at the calyx of Held synapse (Chuhma and Ohmori, 1998; Schneggenburger et al., 1999). This finding suggests that under conditions of normal release probability, individual quanta add up linearly to form an evoked EPSC. The postsynaptic saturation effects described recently by Sun and Wu (2001) for presynaptic step depolarizations do not seem to play a large role for action potential-induced EPSCs under normal conditions, most likely because the probability of vesicle fusion at a given active zone is rather low ( $\approx 0.25-0.4$; see below). The linear relationship in the EPSC variance-mean plot is also consistent with the suggestion that synaptic depression at stimulation frequencies up to $10 \mathrm{~Hz}$ results almost exclusively from a reduction of the number of quanta released with each presynaptic action potential (von Gersdorff et al., 1997; Weis et al., 1999; Takahashi et al., 2000).

\section{Possible functional correlate of the binomial parameter $\boldsymbol{N}$}

The binomial model has been found useful for describing the statistics of transmitter release at different synapses, including the crayfish neuromuscular junction (Johnson and Wernig 1971; Zucker, 1973), frog neuromuscular junction (Miyamoto, 1975) 

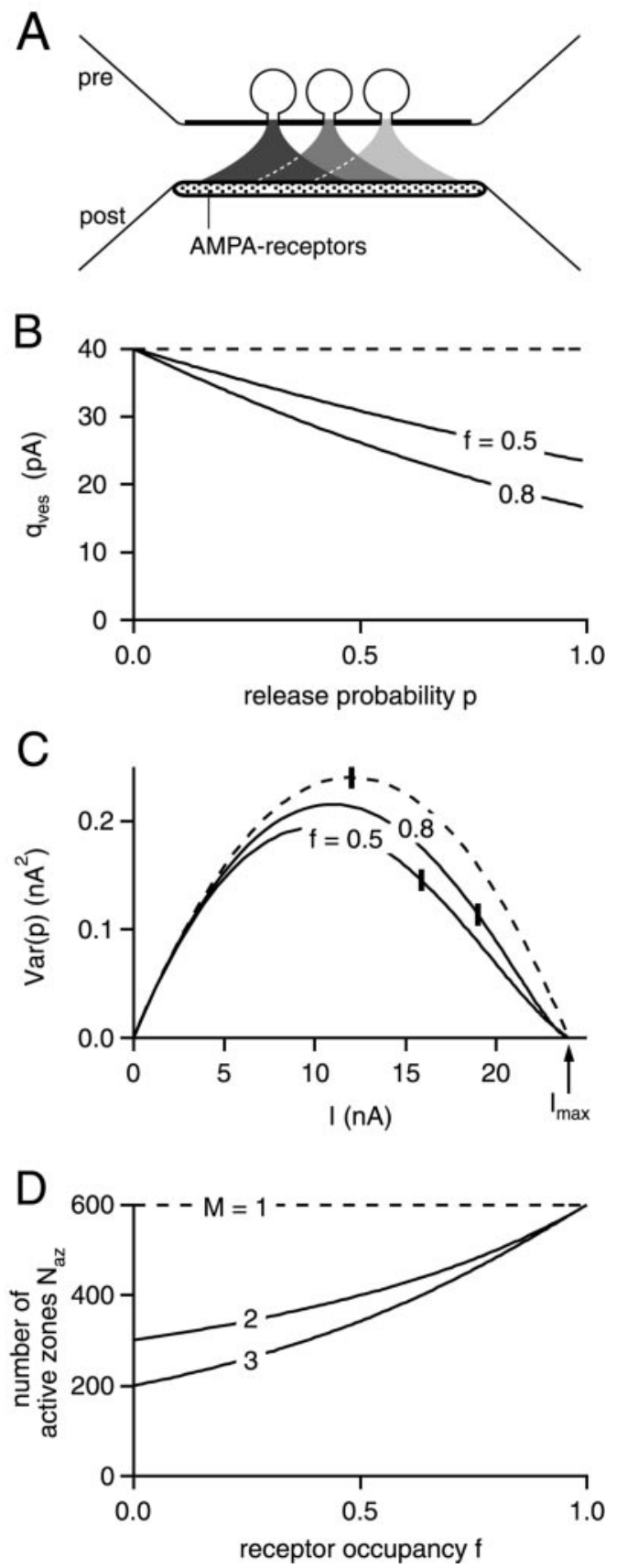

Figure 9. The influence of multivesicular release on the interpretation of the binomial parameter N. A, Schematic representation of the model used here (see Material and Methods for details). It is assumed that $M=3$ vesicles can fuse under conditions of high release probability during a presynaptic action potential, and that transmitter is released onto a common pool of postsynaptic AMPARs. $B$, Plot of average quantal size $q$ per fused vesicle, as a function of release probability, $p$. In $B$ and $C, M$ was set to 3 , and the calculations were made for the indicated values of receptor saturation, $f$. The dashed line in $B-D$ shows the predictions for the case of the one vesicle-one active zone assumption $(M=1)$. $C$, EPSC variancemean plot calculated from Equations 7 and 8, for a synapse with $N_{a z}$ active zones. $N_{a z}$ was adjusted to produce a fixed value of $I_{\max }(24 \mathrm{nA})$, irrespective of the values for $f$ and $M$. Vertical bars indicate the position in the curves corresponding to release probability $p$ of 0.5 . $D$, Number of active zones necessary to produce a maximal EPSC amplitude of $24 \mathrm{nA}$, as a function of receptor occupancy, $f$. Note that for the one vesicle-one active zone assumption $(M=1), N_{a z}$ is equal to the binomial parameter $N$ (600 in this case), independent of postsynaptic receptor occupancy $f$. This is not the case if more than one vesicle $(M=2,3)$ is allowed to fuse at each active zone. and inhibitory synapses on goldfish Mauthner cells (Korn et al., 1981). More recently, simplified multinomial models based on binomial statistics of release have been used to describe EPSC fluctuations in mammalian central synapses (Silver et al., 1998; Reid and Clements, 1999; Oleskevich et al., 2000). In some studies, it has been suggested that the binomial parameter $N$ corresponds to the number of morphologically defined active zones (Zucker, 1973; Korn et al., 1981; Oleskevich et al., 2000). In other studies, the binomial parameter $N$ was assumed to reflect the number of "functional release sites" (Silver et al., 1998).

For the derivation of the binomial model for transmitter release, the entity "release site" does not contain an obvious structural correlate, such as a morphologically defined active zone. A release site in binomial terms is defined as a site at which zero, or maximally one vesicle can be released per stimulus (Quastel, 1997). Electron microscopic images of active zones, however, show several docked vesicles (Harris and Sultan, 1995; Schikorski and Stevens, 1997; Lübke et al., 2000), and there is evidence that under conditions of high release probability, more than one vesicle can be released at single active zones ("multivesicular release"; Tong and Jahr, 1994; Auger et al., 1998). If multivesicular release is taken into account, then the degree of saturation of postsynaptic receptors after the release of a single vesicle becomes an important parameter for the interpretation of the binomial parameter $N$ obtained from variance-mean analysis.

This can be seen in the model calculations shown in Figure 9. Here, we have assumed that a number of vesicles, $M$, can be released at each active zone, and that the synaptic connection is made up of a number of active zones, $N_{a z}$ (see Materials and Methods). With the possibility of multivesicular release $(M>1)$, the mean quantal size that can be induced by each vesicle decreases with increasing release probability (Fig. 9B), and the EPSC amplitude versus release probability relation will show a saturating behavior (data not shown). The EPSC variance-mean relation (Fig. 9C) shows identical initial slopes under these assumptions, because the effective quantal size is constant in the limit of low release probability (Fig. 9B). However, under the assumption of multivesicular release $(M=3$ vesicles in Fig. 9B, $C)$, the maximum of the EPSC variance-mean relationship no longer corresponds to a release probability of 0.5 (see vertical bars in Fig. $9 C)$. Also, the overall shape of the variance-mean plot becomes slightly asymmetric, reflecting the reduced effective quantal size at release probabilities close to 1 . The slight asymmetry, however, should not lead to a large $(>10 \%)$ underestimation of the maximal current $I_{\text {max }}$ from extrapolations of parabola fits, as estimated by fits to the model predictions (data not shown). Dividing $I_{\text {max }}$ (24 nA in our example) by the quantal size $q$ will give the binomial parameter $N$. Nevertheless, the number of active zones $N_{a z}$ needed to generate the maximal EPSC is considerably smaller than the binomial parameter $N$ for the case of $M>1$, especially when postsynaptic receptor occupancy is small (Fig. 9D).

For a correct interpretation of the binomial parameter $N$, one therefore needs to know whether multivesicular release occurs at high $p$. If it does occur, one further needs to know to what degree postsynaptic receptors are saturated after the release of a single vesicle. From the experiments made in the presence of kyn, we have obtained evidence for an increased effective glutamate concentration under conditions of high $p$ (Fig. 8, Table 2). This could either be caused by multivesicular release (Tong and Jahr, 1994), and/or by spillover of glutamate from neighboring active zones (Silver et al., 1996). Considering published model calculations (Rusakov et al., 1999), it might be considered unlikely that during 
the short time intervals relevant for the analysis of peak EPSCs $(<0.5 \mathrm{msec})$, spillover from neighboring active zones was significant. On the other hand, release activity at surrounding active zones $(\approx 0.55 \mu \mathrm{m}$ distance to the nearest neighbors at the calyx of Held; Lübke et al., 2000) might influence the rate of decay of the glutamate transient at a given active zone, and thereby the occupancy of postsynaptic AMPARs (R. A. Silver, personal communication). At times longer than a few milliseconds, a significant build-up of glutamate originating from neighboring active zones is expected (Neher and Sakaba, 2001).

Taken together, the experimental evidence for a reduced blocking efficiency of kyn at high $p$ (Fig. $8 A, B)$ can be explained by a certain degree of multivesicular release, although rapid glutamate spillover might also explain part of this effect. Taking into account previous evidence that AMPARs are not saturated by the release of a single vesicle (Silver et al., 1996; Liu et al., 1999; Ishikawa et al., 2000), we conclude that the binomial parameter $N(637 \pm 113$; mean \pm SEM of $n=15$ cells shown in Tables 1,2) must be regarded as an upper limit estimate (Fig. 9D) of the number of functional active zones contributing to transmission at the calyx of Held synapse. Although the binomial parameter $N$ showed a considerable cell-to-cell variability, it is, on average, in good agreement with a recent report in which the number of morphologically defined active zones was counted (Lübke et al., 2000). Using electron microscopy and serial reconstruction of two rat calyces of Held of a similar developmental stage, these authors have counted $\approx 500$ morphologically defined active zones (J. Lübke, personal communication).

\section{Comparison with previous pool size estimates}

In some recent studies, pool sizes at the calyx of Held synapse have been probed using deconvolution analysis of EPSCs evoked by strong presynaptic $\mathrm{Ca}^{2+}$ stimulation. The stimuli were applied either by flash-photolysis of caged $\mathrm{Ca}^{2+}$ in the presynaptic terminal (Schneggenburger and Neher, 2000), or by direct presynaptic depolarization (Sakaba and Neher, 2001). These studies have revealed pool sizes in the range of several thousand vesicles (1800 and 2200 on average; Schneggenburger and Neher, 2000 and Sakaba and Neher 2001, respectively). Using capacitance measurements and presynaptic depolarizations, an even larger pool size has been reported (3300-5200 vesicles; Sun and Wu, 2001). Comparing these numbers with the upper limit estimate of the number of active zones $(\approx 600)$ estimated here, it follows that during strong presynaptic $\mathrm{Ca}^{2+}$ stimulation, more than one vesicle is released at each active zone (see also Sun and Wu, 2001).

The pool size estimates by Schneggenburger and Neher (2000), Sakaba and Neher (2001), and Sun and Wu (2001) $(\approx 1800,2200$, and $>3000$, respectively) are significantly larger than those based on summing up peak EPSC amplitudes during trains of afferent fiber stimulations ( $\approx 700$, Schneggenburger et al., $1999 ; \approx 810$, Bollmann et al., 2000; $\approx 380-940$ at various stages of development, Taschenberger and von Gersdorff, 2000). This might indicate that during short high-frequency trains, only a subset of the pool can be released, maybe because of heterogeneity of release probability between vesicles in the releasable pool (Sakaba and Neher, 2001). Also, the analysis of peak EPSC amplitudes does not account for asynchronously released vesicles which, on the other hand, will be detected by the deconvolution method (Neher and Sakaba, 2001) and by capacitance measurements (Sun and $\mathrm{Wu}, 2001$ ). Additionally, if significant desensitization of AMPAR had contributed to depression in some of the previous studies performed without CTZ, an underestimation of the number of released quanta would have resulted.

\section{Release probability at an active zone}

From our data obtained with $10 \mathrm{~Hz}$ stimulation at $2 \mathrm{~mm}\left[\mathrm{Ca}^{2+}\right]$, $1 \mathrm{~mm}\left[\mathrm{Mg}^{2+}\right]$ (Figs. 1,2), the quantal content of an EPSC evoked by a presynaptic action potential can be calculated. The resulting value (157 quanta on average; range, 60-400 quanta in $n=8$ cells) is in good agreement with previous estimates (Borst and Sakmann, 1996; Schneggenburger et al., 1999). Assuming that transmission takes places at a range of 400-600 functional active zones (see above), a rough estimate of the average probability of vesicle fusion at each active zone can be obtained with $0.25-0.4$. This rather small release probability per active zone resembles the values reported for cultured hippocampal synapses (Rosenmund et al., 1993; Murthy et al., 1997). With the techniques used in these previous studies, it was possible to study the distribution of $p$ between different active zones, and the obtained values ranged between 0.1 and 0.5 (Rosenmund et al., 1993), and in a slightly wider range in the study of Murthy et al. (1997), although most active zones were found to have $p<0.3$. The estimate of average release probability per active zone reported here $(p=$ $0.25-0.4)$ is, however, significantly smaller than the value of $p=$ 0.87 obtained by Chuhma and Ohmori (1998).

Considering the pool size estimates of Schneggenburger and Neher (2000), Sakaba and Neher (2001), and Sun and Wu (2001), it is seen that the average release probability for each vesicle in the releasable pool must be smaller than 157 of 1800 , or $<10 \%$. It will be interesting to examine whether all vesicles in the relatively large pool of releasable vesicles have equal release probability during action potential-evoked EPSCs or whether a subset of rapidly fusing vesicles (Sakaba and Neher, 2001) might preferentially support transmitter release during the initial phase of highfrequency trains of presynaptic activity.

\section{REFERENCES}

Auger C, Kondo S, Marty A (1998) Multivesicular release at single functional synaptic sites in cerebellar stellate and basket cells. J Neurosci 18:4532-4547.

Bollmann J, Sakmann B, Borst J (2000) Calcium sensitivity of glutamate release in a calyx-type terminal. Science 289:953-957.

Borst JGG, Sakmann B (1996) Calcium influx and transmitter release in a fast CNS synapse. Nature 383:431-434.

Borst JGG, Helmchen F, Sakmann B (1995) Pre- and postsynaptic whole-cell recordings in the medial nucleus of the trapezoid body of the rat. J Physiol (Lond) 489:825-840.

Brown TH, Perkel DH, Feldman MW (1976) Evoked neurotransmitter release: statistical effects of nonuniformity and nonstationarity. Proc Natl Acad Sci USA 73:2913-2917.

Chuhma N, Ohmori H (1998) Postnatal development of phase-locked high-fidelity synaptic transmission in the medial nucleus of the trapezoid body of the rat. J Neurosci 18:512-520.

Clements JD, Silver RA (2000) Unveiling synaptic plasticity: a new graphical and analytical approach. Trends Neurosci 23:105-113.

Diamond JS, Jahr CE (1997) Transporters buffer synaptically released glutamate on a submillisecond time scale. J Neurosci 17:4672-4687.

Forsythe ID, Barnes-Davies M (1993) The binaural auditory pathway: exitatory amino acid receptors mediate dual timecourse excitatory postsynaptic currents in the rat medial nucleus of the trapezoid body. Proc R Soc Lond B Biol Sci 251:151-157.

Forsythe ID, Tsujimoto T, Barnes-Davies M, Cuttle MF, Takahashi T (1998) Inactivation of presynaptic calcium current contributes to synaptic depression at a fast central synapse. Neuron 20:797-807.

Frerking M, Wilson M (1996) Effects of variance in mini amplitude on stimulus-evoked release: a comparison of two models. Biophys J 70:2078-2091.

Geiger JRP, Melcher T, Koh D-S, Sakmann B, Seeburg PH, Jonas P, Monyer H (1995) Relative abundance of subunit mRNAs determines gating and $\mathrm{Ca}^{2+}$-permeability of AMPA receptors in principal neurons and interneurons in rat CNS. Neuron 15:193-204.

Harris KM, Sultan P (1995) Variation in the number, location and size of synaptic vesicles provides an anatomical basis for the non-uniform 
probability of release at hippocampal CA1 synapses. Neuropharmacology 34:1387-1396.

Heinemann SH, Conti F (1992) Nonstationary noise analysis and application to patch clamp recordings. Methods Enzymol 207:131-148.

Ishikawa T, Sahara Y, Takahashi T (2000) A single packet of glutamate does not saturate postsynaptic AMPA receptors at the calyx of Held synapse. Soc Neurosci Abstr 26:422.1.

Johnson EW, Wernig A (1971) The binomial nature of transmitter release at the crayfish neuromuscular junction. J Physiol (Lond) 218:757-767.

Korn H, Triller A, Mallet A, Faber DS (1981) Fluctuating responses at a central synapse: $n$ of binomial fit predicts number of stained presynaptic boutons. Science 213:898-901.

Lenn NJ, Reese TS (1966) The fine structure of nerve endings in the nucleus of the trapezoid body and the ventral cochlear nucleus. Am J Anat 118:375-390.

Liu G, Choi S, Tsien RW (1999) Variability of neurotransmitter concentration and nonsaturation of postsynaptic AMPA receptors at synapses in hippocampal cultures and slices. Neuron 22:395-409.

Lübke JHR, Sätzler K, Söhl L, Roth A, Eils R, Frotscher M, Sakmann B (2000) The calyx of Held: 3-D reconstruction and quantitative analysis of its morphology. Soc Neurosci Abstr 26:252.3.

Matveev V, Wang X-J (2000) Implications of all-or-none synaptic transmission and short-term depression beyond vesicle depletion: a computational study. J Neurosci 20:1575-1588.

Miyamoto MD (1975) Binomial analysis of quantal transmitter release at glycerol treated frog neuromuscular junctions. J Physiol (Lond) 250:121-142.

Murthy VN, Sejnowski TJ, Stevens CF (1997) Heterogeneous release properties of visualized individual hippocampal synapses. Neuron 18:599-612.

Neher E, Sakaba T (2001) Combining deconvolution and noise analysis for the estimation of transmitter release rates at the calyx of Held. J Neurosci 21:444-461.

Oleskevich S, Clements J, Walmsley B (2000) Release probability modulates short-term plasticity at a rat giant terminal. J Physiol (Lond) 524:513-523.

Otis T, Zhang S, Trussell LO (1996) Direct measurement of AMPA receptor desensitization induced by glutamatergic synaptic transmission. J Neurosci 16:7496-7504.

Partin KM, Patneau DK, Mayer ML (1994) Cyclothiazide differentially modulates desensitization of $\alpha$-amino-3-hydroxy-5-methyl-4isoxazolepropionic acid receptor splice variants. Mol Pharmacol 46:129-138.

Quastel DMJ (1997) The binomial model in fluctuation analysis of quantal neurotransmitter release. Biophys J 72:728-753.

Reid CA, Clements JD (1999) Postsynaptic expression of long-term potentiation in the rat dentate gyrus demonstrated by variance-mean analysis. J Physiol (Lond) 518:121-130.

Rosenmund C, Clements JD, Westbrook GL (1993) Nonuniform probability of glutamate release at a hippocampal synapse. Science 262:754-757.

Rowland KC, Irby NK, Spirou GA (2000) Specialized synapseassociated structures within the calyx of Held. J Neurosci 20:9135-9144.
Rusakov DA, Kullmann DM, Stewart MG (1999) Hippocampal synapses: do they talk to their neighbours? Trends Neurosci 22:382-388.

Sakaba T, Neher E (2001) Quantitative relationship between transmitter release and calcium current at the calyx of Held synapse. J Neurosci 21:462-476.

Scheuss V, Neher E (2001) Estimating synaptic parameters from mean, variance and covariance in trains of synaptic responses. Biophys $\mathrm{J}$, in press.

Schikorski T, Stevens CF (1997) Quantitative ultrastructural analysis of hippocampal excitatory synapses. J Neurosci 17:5858-5867.

Schneggenburger R, Neher E (2000) Intracellular calcium dependence of transmitter release rates at a fast central synapse. Nature 406:889-893.

Schneggenburger R, Meyer AC, Neher E (1999) Released fraction and total size of a pool of immediately available transmitter quanta at a calyx synapse. Neuron 23:399-409.

Sigworth F (1980) The variance of sodium current fluctuations at the node of Ranvier. J Physiol (Lond) 307:97-129.

Silver RA, Cull-Candy SG, Takahashi T (1996) Non-NMDA glutamate receptor occupancy and open probability at a rat cerebellar synapse with single and multiple release sites. J Physiol (Lond) 494:231-250.

Silver RA, Momiyama A, Cull-Candy SG (1998) Locus of frequencydependent depression identified with multiple-probability fluctuation analysis at rat climbing fibre-Purkinje cell synapses. J Physiol (Lond) 510:881-902.

Sun J-Y, Wu L-G (2001) Fast kinetics of exocytosis revealed by simultaneous measurements of presynaptic capacitance and postsynaptic currents at a central synapse. Neuron 30:171-182.

Takahashi T, Hori T, Kajikawa Y, Tsujimoto T (2000) The role of GTP-binding protein activity in fast central synaptic transmission. Science 289:460-463.

Taschenberger H, v Gersdorff H (2000) Fine-tuning an auditory synapse for speed and fidelity: Developmental changes in presynaptic waveform, EPSC kinetics, and synaptic plasticity. J Neurosci 20:9162-9173.

Tong G, Jahr CE (1994) Multivesicular release from excitatory synapses of cultured hippocampal neurons. Neuron 12:51-59.

Traynelis SF (1998) Software-based correction of single compartment series resistance errors. J Neurosci Meth 86:25-34.

Trussell LO, Zhang S, Raman IM (1993) Desensitization of AMPA receptors upon multiquantal neurotransmitter release. Neuron 10:1185-1196.

von Gersdorff H, Schneggenburger R, Weis S, Neher E (1997) Presynaptic depression at a Calyx synapse: the small contribution of metabotropic glutamate receptors. J Neurosci 17:8137-8146.

Wang L-Y, Kaczmarek LK (1998) High-frequency firing helps replenish the readily releasable pool of synaptic vesicles. Nature 394:384-388.

Weis S, Schneggenburger R, Neher E (1999) Properties of a model of $\mathrm{Ca}^{2+}$-dependent vesicle pool dynamics and short term synaptic depression. Biophys J 77:2418-2429.

Wu L-G, Borst JGG (1999) The reduced release probability of releasable vesicles during recovery from short-term synaptic depression. Neuron 23:821-832.

Zucker R (1973) Changes in the statistics of transmitter release during facilitation. J Physiol (Lond) 229:787-810. 